\title{
Precipitation and texture effects on the weathering of young Mauna Loa basalts, and the early stages of soil formation
}

\author{
SHIKMA ZAARUR ${ }^{1}$, MAOR KADURI ${ }^{2}$ \\ ${ }^{1}$ Dept. of Soils and Water Sciences, The Hebrew University \\ of Jerusalem, Israel. Shikma.zaarur@mail.huji.ac.il \\ ${ }^{2}$ Institute of Earth Sciences, The Hebrew University of \\ Jerusalem, 91904, Israel.maorkaduri@gmail.com
}

The weathering of silicate minerals is among the most important processes in soil formation and the development of the critical zone; it has long been recognized that parent material, climate and time are amongst the key factors that govern and control this process. In a developed critical zone, with an established soil profile, the silicate weathering and release of nutrients likely occur at the rock-soil interface, deep in the critical zone where primary minerals are exposed to reactive fluids (Buss et al., 2017). In this study we examine the very early stages of development of the critical zone. We focus on the weathering of basalts ranging in age from the historical 1880 Mauna Loa lava flow to $\sim 16,000$ years before present, that are not covered by a soil profile.

Basalt samples (pāhoehoe) were collected from the windward ( $\sim 3 \mathrm{~m}$ annual rainfall) and leeward ( $\sim \mathrm{m}$ annual rainfall) flanks of Mauna Loa volcano, Hawai'i. On the windward side, the youngest basalt is covered by dense vegetation but shows little to no chemical alteration; as the basalts increase in age, weathering of the matrix progresses from the surfaces of the basalt and secondary minerals fill the vesicles. In contrast, even after $\sim 16,000$ years, the weathering of the basalts (covered by dense vegetaion), on the leeward side, is mostly restricted to the pāhoehoe surface. In addition to the effects of precipitation on the progression of weathering, textural variance primarily related to porosity and surface area are critical to weathering advancement. Weathering intensities varied from moderate alteration limited to the vesicles in the basalt, to near complete chemical weathering of the fine ' $a$ 'a clinker within a single basalt flow.

Our results demonstrate the large range of weathering rates that can occur within a small but heterogeneous area due to the differences in environmental conditions (e.g., precipitation) and the internal properties of the parent material (e.g., porosity). Furthermore, they point to the intricacies of the early stages of soil and critical zone development.

Ref: Buss et al., 2017. GCA (196) 